Agnieszka Chambellan

\title{
Europäisierung des Reisevertragsrechts
}

Die Mängelrechte des Reisenden im deutsch-polnischen Rechtsvergleich

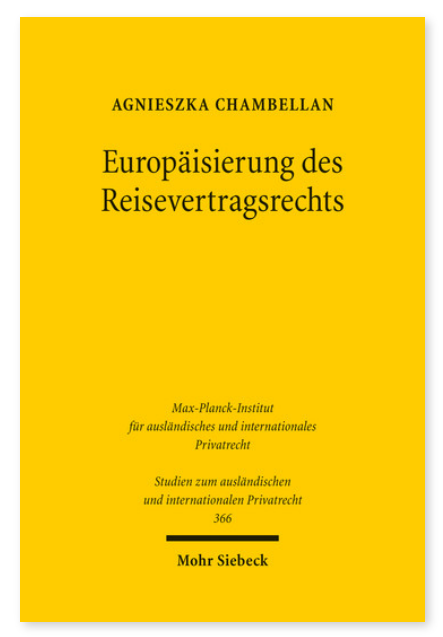

2016. XX, 216 Seiten. StudIPR 366

ISBN 978-3-16-154059-2

DOI 10.1628/978-3-16-154059-2

eBook PDF $69,00 €$

ISBN 978-3-16-154043-1

fadengeheftete Broschur 69,00€
Das Reiserecht mit seinem grenzüberschreitenden Charakter, sich stetig wandelnder Rechtsprechung und dem unterschiedlichen länderabhängigen Verbraucherschutzniveau stellt ein komplexes Rechtsgebiet dar. Agnieszka Chambellan vergleicht die deutschen und polnischen Systeme bezüglich der reisevertraglichen Mängelrechte. Obwohl beide Systeme mit dem europäischen Recht, insbesondere mit der Pauschalreiserichtlinie 90/314/EWG, übereinstimmen müssen, weisen sie unterschiedliche Regelungen auf. Im Zusammenhang damit arbeitet die Autorin Unterschiede und Gemeinsamkeiten einzelner Mängelrechte heraus und beurteilt diese Regelungen hinsichtlich des Verbraucherschutzes.

Neben einem Vergleich der historischen Entwicklungen des Reiserechts in beiden Ländern und aktuellen Tendenzen beschreibt sie die wichtigsten Definitionen und Probleme des Reiserechts und setzt sich fundiert mit dem Begriff 'Reisemangel' und einzelnen Mängelrechten auseinander.

Agnieszka Chambellan Geboren 1986; Studium der Rechtswissenschaften an der Universität Torun (Polen); Praktika in Rechtsanwaltskanzleien in Torun, Warschau und Hamburg und bei der polnischen Botschaft in Mexiko; LL.M.- und Promotionsstudium an der Universität Regensburg als Stipendiatin der Konrad-Adenauer-Stiftung; Rechtsanwältin in Polen (radca prawny); derzeit transaction lawyer bei einer international tätigen Rechtsanwaltskanzlei.

Jetzt bestellen:

https://mohrsiebeck.com/buch/europaeisierung-des-reisevertragsrechts-9783161540592?no_cache=1 order@mohrsiebeck.com

Telefon: +49 (0)7071-923-17

Telefax: +49 (0)7071-51104 